\title{
Decision aid model for asphalt mixture choice
}

\author{
Dr. N. Bueche ${ }^{\mathrm{a}^{*}}$, Prof. A.-G. Dumont ${ }^{\mathrm{a}}$ \\ ${ }^{a}$ Ecole Polytechnique Fédérale de Lausanne, Traffic Facilities Laboratory, Switzerland
}

\begin{abstract}
Warm Mix Asphalt (WMA) represents widely used alternative to hot mix asphalt (HMA), this in order to decrease the energy consumption and environmental load. Numerous WMA products can be found and the choice of the most favourable mixture is not necessarily straightforward. In order to achieve this, an innovative methodology has been developed. This methodology permits to consider various qualitative and quantitative criteria such as mechanical performances, production complexity and sustainability, but also includes a life cycle analysis of the emissions (greenhouse gas), energy and costs. The process as developed and implemented comprises four independent levels, each bringing its own contribution to the decision making procedure. The model finally proposed permits to compare different types of asphalt mixtures and assists in a very flexible way in the decision making process.
\end{abstract}

Keywords: warm mix asphalt; energy; emissions; sustainable development; multiple attribute decision making; life cycle inventory

\section{Résumé}

Les enrobés tièdes représentent une alternative aux enrobés à chaud largement utilisée afin de diminuer la consommation énergétique et les émissions. De nombreux produits pour la fabrication d'enrobés tièdes peuvent être trouvés et le choix de la meilleures alternative n'est pas nécessairement aisé. Afin d'assister dans ce processus, une méthodologie innovante a été développée. Cette méthodologie permet de considérer différents critères qualitatifs et quantitatifs tels que les performances mécaniques, la complexité de production ou le potentiel de recyclabilité, mais inclut également une analyse sur le cycle de vie des émissions (gaz à effet de serre), de l'énergie et des coûts. Le processus de décision tel que développé et implémenté comprend quatre niveaux indépendants, chacun apportant sa propre contribution. Le modèle finalement proposé permet de comparer différentes variantes d'enrobés et assiste de manière très flexible dans le processus de décision.

Mots-clé: enrobé tiède ; énergie ; émissions, développement durable ; aide multicritère à la décision ; analyse du cycle de vie

\footnotetext{
${ }^{*}$ Corresponding author information: Tel.: +41 2169323 45; Fax: +41 216932349

E-mail address: nicolas.bueche@epfl.ch.
}
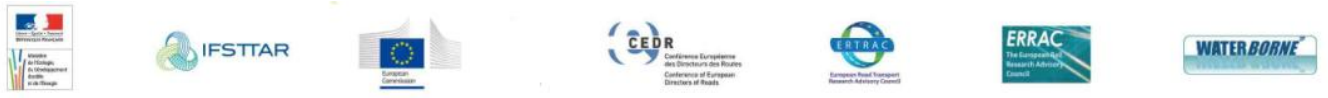


\section{Background and objectives}

Warm Mix Asphalt (WMA) represents widely used alternative to hot mix asphalt (HMA), this in order to decrease the energy consumption and environmental load. Numerous WMA products can be found and the choice of the most favourable mixture for a given project is not necessarily straightforward. Few GHG calculators currently available are able to perform a comparison at the asphalt mixture scale and they only consider some limited criteria. However, in a decision making process, the choice should take into account some additional aspects such as mechanical performances, costs, production complexity or sustainability. Indeed, the final choice depends on both qualitative and quantitative criteria that can also be different in function of the user sensitivity or project requirements.

To redress this situation, a multi-criteria model has been developed and implemented in the framework of Bueche (2011). The proposed model aims at comparing different types of asphalt mixtures and assisting the road owner in the decision making process.

\section{Model architecture}

The developed model aims at providing a help in the decision process of the asphalt mixture choice. In order to achieve this, the model should be able to take into account various parameters that can be either quantitative or qualitative. Besides, a high model flexibility is also required, this in order to adapt it in function of the user and/or project requirements and boundaries.

Basically, the model is divided into two parts that will be further detailed. In the first part, the data to be used for the decision analysis are generated through a complete life cycle inventory (LCI), and the mechanical performances of the asphalt mixtures (i.e. alternatives) are also entered and evaluated. The second part of the model consists in the decision making process. An overview of the model is presented in Fig. 1. while the various components will be detailed hereafter. 


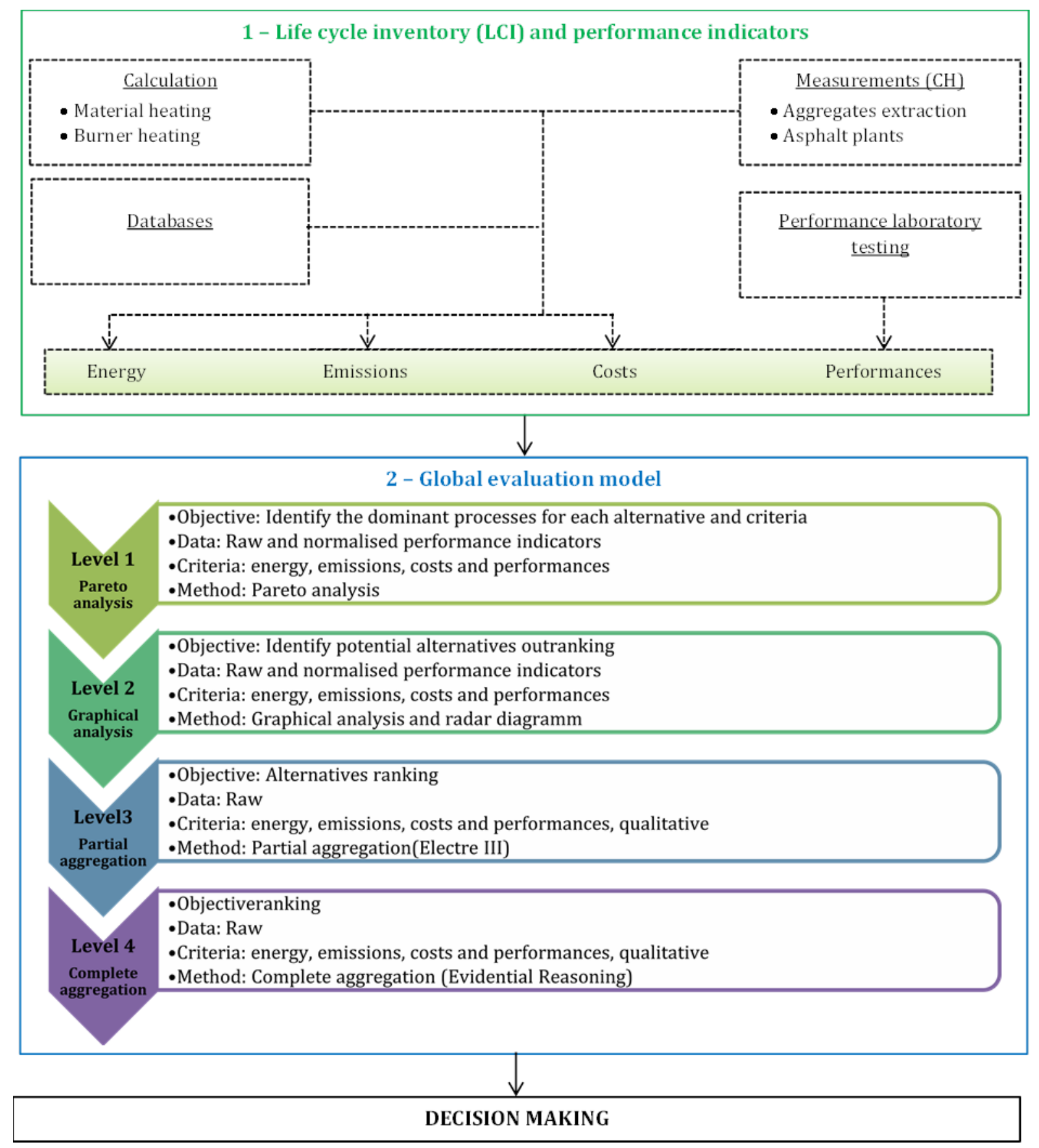

Fig. 1. Overview of the multi-criteria model architecture

\subsection{Life cycle inventory and performance indicators (Model part 1)}

The first part of the model consists in developing the various indicators that will be further used in the multi attribute decision making (MADM) process. The proposed multi-criteria model takes into account greenhouse gas (GHG) emissions $\left(\mathrm{CO}_{2}, \mathrm{CH}_{4}, \mathrm{~N}_{2} \mathrm{O}\right)$, energy consumption and economic aspects over the whole life cycle of the asphalt mixture. To achieve this, a life cycle inventory (LCI) is performed according to the boundaries represented in Fig. 2. One can highlight that the system starts with the extraction of the raw material (aggregates, bitumen, ...) and the boundaries has been fixed to the end of the compaction process. Thus, the recycling 
procedure after the end of service life is not implemented, this in particular because of the high uncertainty related.

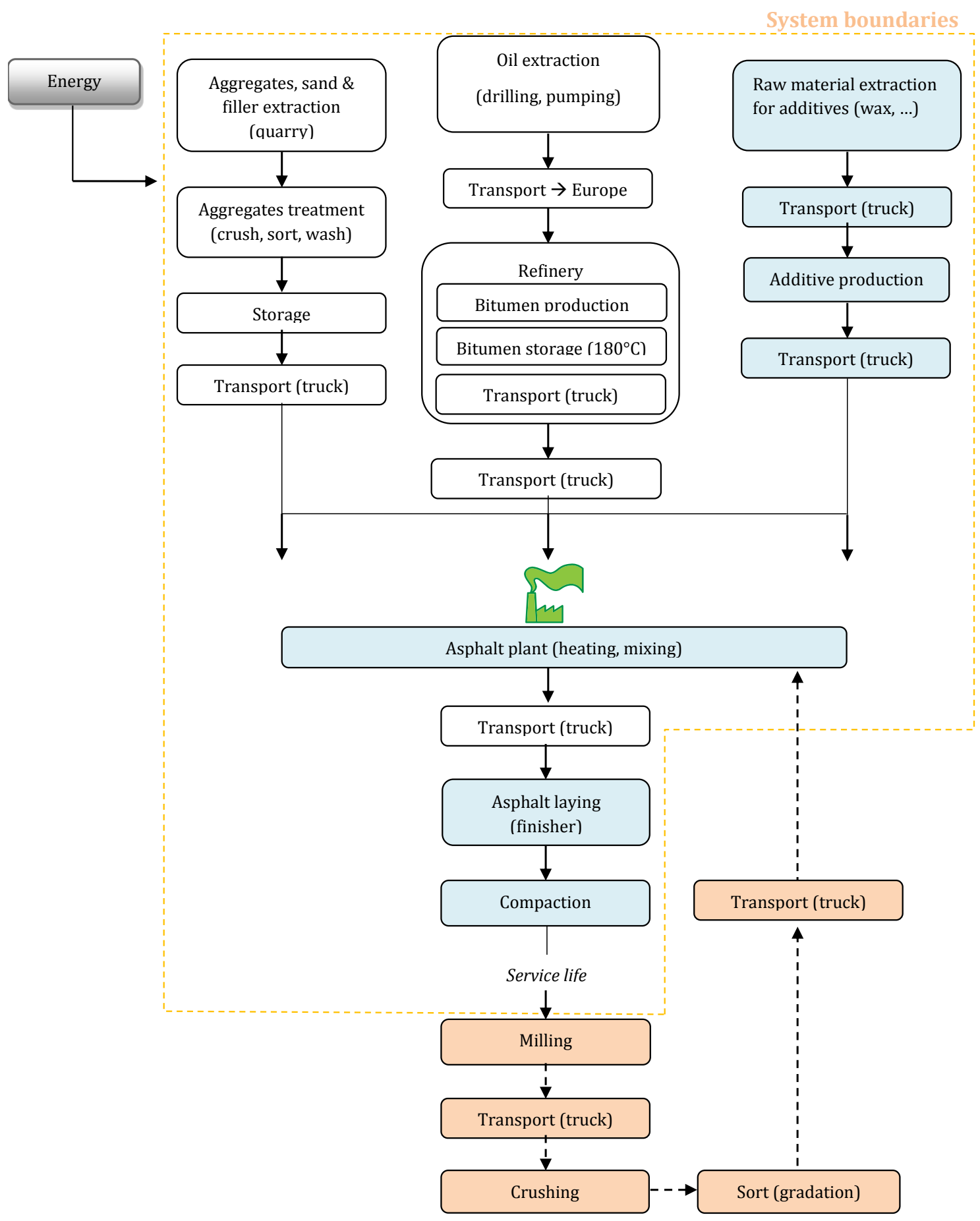

Fig. 2. Overview of the multi-criteria model architecture

The life cycle inventory (LCI) is a crucial component of the evaluation procedure that requires a large amount of information. Various data sources can be used in order to perform a LCI (Fig. 1), the following have been implemented in the model: 
- Measurements: A database containing the measurements of energy and emissions for some representative Swiss plants and quarries is proposed. This database concerns only some specific processes that proved to be dominant over the asphalt mixture life cycle.

- Calculation of the asphalt plant energy consumption and air emissions: This calculation tool permits in particular to compare various asphalt mixture technologies produced in similar conditions. It also allows calculating the plant efficiency and performing some sensitivity analysis for the process related to the asphalt mixture production. Some more information can be found in Bueche (2012a).

- Literature data: A database including various representative literature data has been included in the model, allowing the user to make some comparison or consider experiences representative of the project local conditions and industrial development. This database can also be completed with the own user's data.

The mechanical performances of the mixture are also taken into account in the decision process. The considered performances are:

- Water sensitivity (indirect tensile strength ratio ITSR)

- Rutting resistance (wheel tracking tests)

- Fatigue resistance (fatigue test)

Based on the abovementioned performances, two indicators are calculated that are 1) raw indicator i.e. result of the laboratory test and 2) normalised indicator based on the laboratory experience and/or standards. The mechanical performances database was established in the first part of the research Bueche (2011), during which a detailed investigation of various WMA technologies has been carried out.

\subsection{Global evaluation (Model part 2)}

The methodology as developed and implemented comprises four independent levels that are roughly summarised in Fig. 1, each bringing its own contribution to the decision making process.

In the first level, a Pareto representation is used to identify the dominant processes over the lifespan of each asphalt mixture. This first level does not aim at comparing the various alternatives, but focuses on the LCI phases of the asphalt mixtures. The performances and other qualitative criteria are not considered.

A first comparison of the alternatives is conducted at the second evaluation level. To achieve this, various graphical analyses are used in order to highlight the potential outranking alternatives. In these first two levels, raw data are used, without any treatment or weighing. This means also that only quantitative parameters can be taken into account at the second evaluation level.

User preferences and qualitative criteria are introduced at the third analysis level, through the introduction of Multi-attribute Decision Making (MADM) methodologies. There are two main "families" of MADM methods, namely partial and complete aggregation, each having their own distinct advantages and properties. There is no perfect MADM method; the choice of method depends on the type of problem to be solved. Thus, existing methods applied in MADM domains were selected for implementation in the specific context of asphalt mixture evaluation. Besides the quantitative criteria considered in the first two levels, two additional qualitative criteria are added at the third evaluation level:

- Production complexity in plant. The production complexity depends on the type of asphalt mixture. For instance, some WMA technologies might require a foaming nozzle or moisture control system that could increase the production complexity compared to traditional HMA.

- Asphalt mixture sustainability. The sustainability of the asphalt mixture depends in particular on the type and content of additives used in its production.

In the third evaluation level, a partial aggregation method using pseudo-criteria is proposed. The favoured option in this respect was the ELECTRE III method, which has been widely used in the environmental domain (Maystre, Pictet and al. 1994a). This method presents the particular property of considering various outranking degrees by comparison of two alternatives, and does not allow compensation between criteria for a given alternative. This evaluation method also allows the equality between two alternatives.

The fourth evaluation level uses an algorithm derived from the Evidential Reasoning approach. This consists of a complete aggregation method, based on the Dempster-Shafer theory, but modified for application in the 
framework of MADM (Yang and Singh. 1994b). The fourth evaluation level is also the most complex, but it allows the model to take into account the occurrence probability of a given performance, and data unknown. Finally, the utility of each alternative is calculated and the ranking determined according to some transfer function.

The various evaluation levels and the major related characteristics are summarised in the Table 1.

Table 1. Comparison between the various evaluation levels

\begin{tabular}{|c|c|c|c|c|}
\hline Evaluation level & Level 1 & Level 2 & Level 3 & Level 4 \\
\hline Method & Pareto analysis & Graphical / Pareto & Partial aggregation & $\begin{array}{l}\text { Complete } \\
\text { aggregation }\end{array}$ \\
\hline Data treatment & No & No & Yes & Yes \\
\hline User preference (weighing) & No & No & Yes & Yes \\
\hline \multicolumn{5}{|l|}{ Criteria } \\
\hline Energy & Yes & Yes & Yes & Yes \\
\hline Emissions & Yes & Yes & Yes & Yes \\
\hline Costs (energy) & Yes & Yes & Yes & Yes \\
\hline Mech. performances & Yes & Yes & Yes & Yes \\
\hline Qualitative & No & No & No & No \\
\hline Hypothesis & Radar diag. & Radar diag. & Weighing, threshold & $\begin{array}{l}\text { Weighing, matrixes, } \\
\text { utility }\end{array}$ \\
\hline Results & $\begin{array}{l}\text { Dominant unitary } \\
\text { processes }\end{array}$ & Potential outranking & Alternatives ranking & Alternatives ranking \\
\hline Robustness analysis & No & No & Yes & Yes \\
\hline
\end{tabular}

The developed model presents various advantages that are in particular:

- Progressive methodology with different levels, each one contributing to a specific aspect of the evaluation process.

- Evaluation of the solution robustness.

- Probabilistic approach.

- It is not necessary to provide an evaluation every criteria and alternative (unknown).

- Model flexibility and development opportunities in function of the project requirements. For instance, one can consider adding some parameters related to the pavement maintenance, commercial cost of the products or choose to modify the mechanical performances to be considered.

\section{Model implementation and results}

The complete model has been implemented in Visual Basic (VBA) and is distributed free of charge. The model is the property of EPFL-LAVOC and the application/support is conducted within the consulting company Nibuxs in Switzerland (contact author for more information).

An example of model application is proposed in the present chapter with the objective of illustrating the obtained results. Thus, a focus is made on the methodology results, without specific considerations of the alternatives ranking. This aspect is however detailed in Bueche (2011).

\subsection{Problem description and method}

Five different asphalt mixtures (i.e. alternatives) for foundation layer (max. aggregate size $22 \mathrm{~mm}$ ) are compared:

- REF: Reference hot mix asphalt, $\mathrm{T}_{\text {prod }}=155^{\circ} \mathrm{C}$

- ET-C: Warm mix asphalt with wax (3\%/binder) $\mathrm{T}_{\text {prod }}=125^{\circ} \mathrm{C}$

- EP-P: Warm mix asphalt with chemical additive $(0.4 \% /$ binder $), \mathrm{T}_{\text {prod }}=125^{\circ} \mathrm{C}$

- EST: Warm mix asphalt with moisture control and the addition of a vegetal flux $(0.4 \% / \mathrm{binder}), \mathrm{T}_{\text {prod }}=105^{\circ} \mathrm{C}$ 
- EBT: Half warm mix asphalt with moisture a control and addition of a vegetal flux $(3 \% / \mathrm{binder}), \mathrm{T}_{\text {prod }}=95^{\circ} \mathrm{C}$ Except for EBT for which the recipe is slightly different, a similar grading curve and binder content has been used for the various asphalt mixture. This means that only difference between the various asphalt mixtures is the (production and compaction) temperatures as well as the production process and eventual additives.

The application of the methodology requires firstly that the user collects the various data and performs the life cycle inventory. For this example, the mechanical performances have been evaluated through a detailed analysis in laboratory (Bueche, 2011).

Once this first step is achieved, each alternative will be evaluated according to the different criteria (chapter 1.2). This second phase will permit to perform a ranking of the alternatives and is illustrated in the next chapter. Basically, it is recommended to perform the four evaluation stages one after the other. If the second level identifies a complete alternative outranking (i.e. one alternative is the best for every single criteria), then the completion of the level 3 and 4 will only serve in order to evaluate the solution robustness.

\subsection{Results summary}

The results finally obtained during the second phase of the model (decision process) are summarised in the present chapter. A focus is made on the methodology and the type of results that can be obtained; the alternatives comparison is not extensively commented.

In the first evaluation level (Pareto analysis), the dominant processes are highlighted for the various mixture types. Fig. 3 illustrates a Pareto representation for the energy consumption of the reference asphalt mixture. Based on this evaluation level, the dominant processes can be identified and quantified. One can mention that for the various asphalt mixtures, the process requiring the major part of energy is the asphalt plant production that requires approximately $30 \%$ to $50 \%$ of the total energy consumption over the life cycle. The bitumen production represents in general approximately $30 \%$ of the total energy consumption while the laying and compacting phases are almost negligible. Depending on the asphalt mixture type, the production of the additives can represent a substantial part of the total energy consumption and consequently air emissions. For instance, the production of Fischer-Tropsch wax (dosage 3\%/bitumen) represents approximately $14 \%$ of the total energy consumption. This illustrates that the additives production cannot be systematically neglected and it has to be evaluated for each case separately.

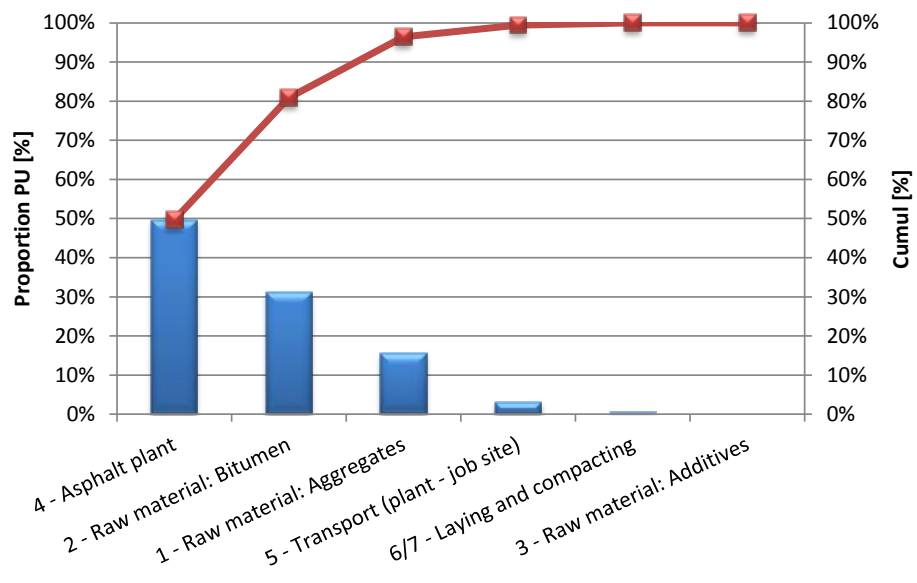

Fig. 3. Level 1: Identification of dominant processes (REF)

The various alternatives are compared in the second evaluation level, this considering the raw results of the quantitative parameters evaluation. Fig. 4. illustrates the obtained results for the five asphalt mixture types. This representation permits to highlight potential alternatives outranking i.e. if an alternative is better than the other alternatives for every single criteria. This type of representation as the advantage of being intuitive and easy to understand, but also presents some limits such as: 
- The application of radar representation requires the uses of normalisation factors that will affect the graphical representation and consequently the perception of the results.

- No quantification of the alternatives outranking degree.

- No consideration of qualitative criteria without specific data treatment.

Based on these comments and due to the fact that no alternative outranking can be identified for the present case, it is necessary to continue the analysis with some specific MADM methods. This will be done in the third and fourth evaluation levels.

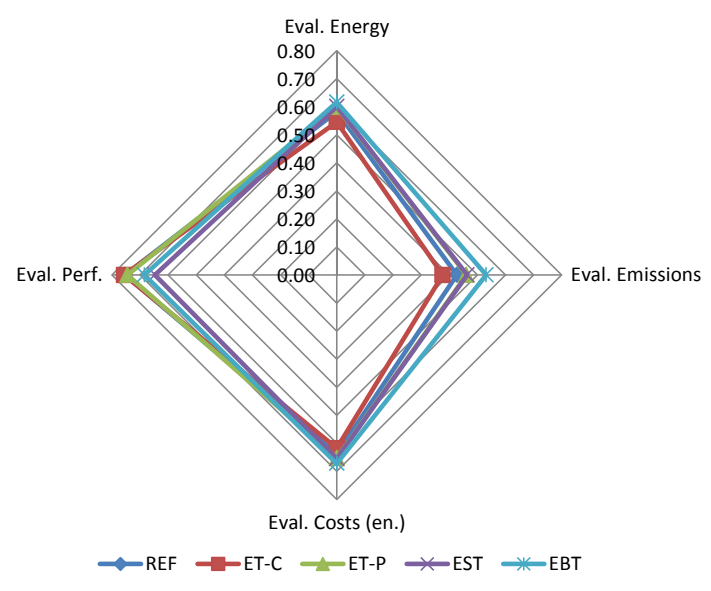

Fig. 4. Level 2: Graphical analysis of the various alternatives

The third evaluation level implies the application of a partial aggregation method in order to obtain an alternative ranking. The results obtained in this evaluation level are consistent with the results obtained in the fourth evaluation level that are illustrated below. The method applied in the fourth evaluation level (complete aggregation) consists in calculating, for each alternative (i.e. asphalt mixture) a belief degree in function of the evaluation level (poor, low, medium, good, excellent). The results are illustrated in Fig. 5 where one can see that the alternative ET-C (red line) has a belief degree of approximately $60 \%$ for a poor performance. On the other hand, alternative REF (dark blue) has a belief degree of $55 \%$ for a medium performance. In the figure below, the "unknown" part corresponds to the probabilistic part related to data unknown while the probabilistic aspects of the evaluation level are also taken into account.

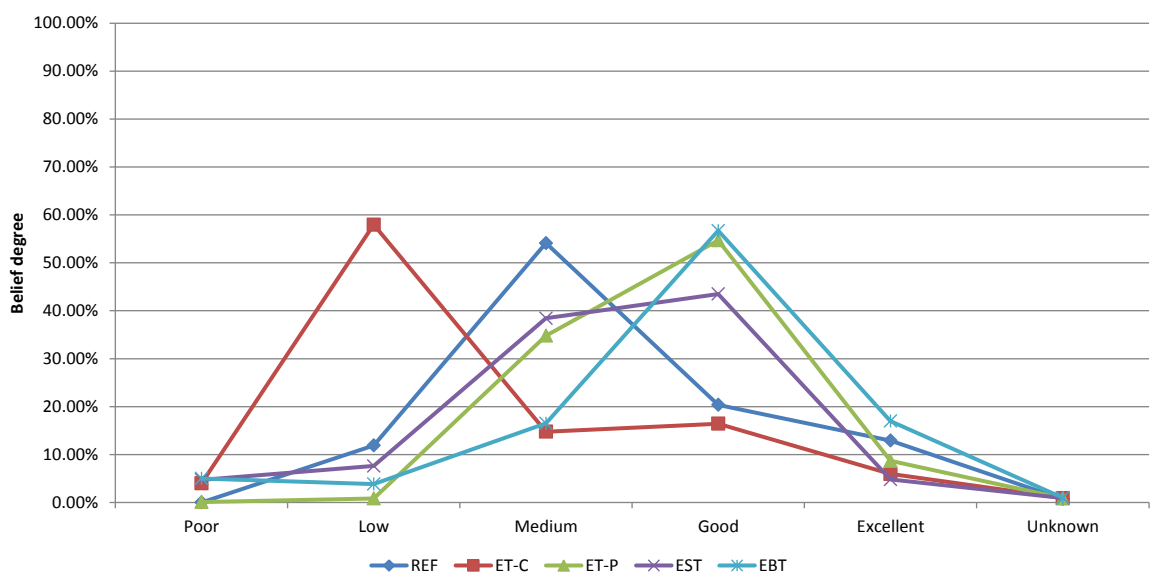

Fig. 5. Level 4: Calculation of the belief degree - complete aggregation

This type of representation (i.e. belief degree) provides a first idea of the various alternatives evaluation and ranking. It is however difficult to obtain the exact ranking of the alternatives. To do this, the complete 
aggregation method requires the calculation of the utility related to each alternative. The result of the utility calculation is presented in the Fig. 6 where a high utility means that the alternative will get a higher ranking.

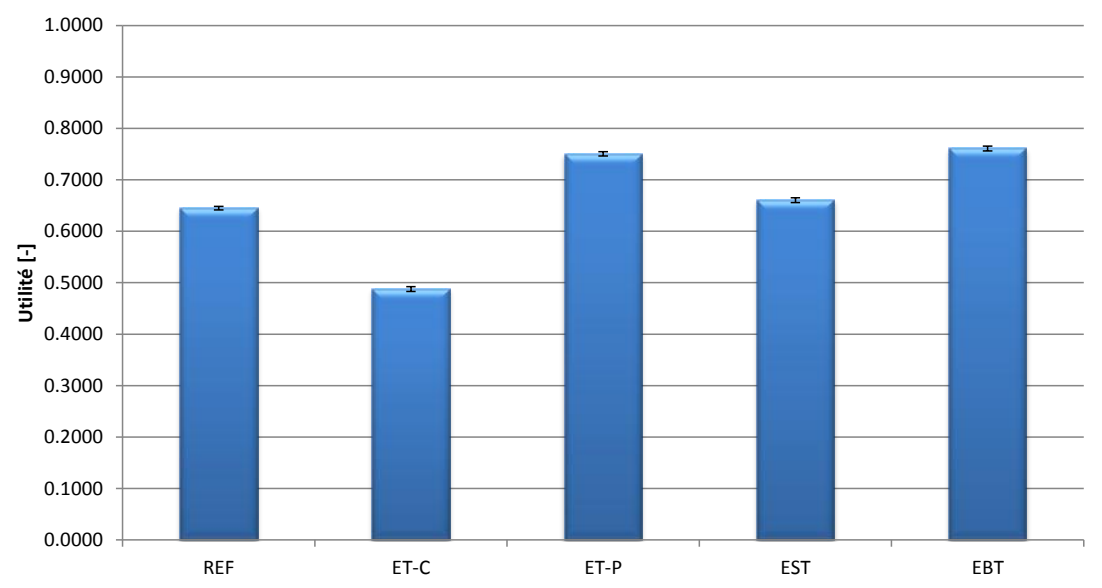

Fig. 6. Level 4: Alternatives ranking (utility) - complete aggregation

As detailed, the evaluation levels 3 and 4 permit to provide a ranking of the alternatives by applying different types of MADM. The robustness of the ranking can be calculated in a last phase, by varying various parameters related to the evaluation methods or by varying the weighing. By doing this, one consider that the ranking obtained is the solution of the problem, and the stability of this solution is assessed through the robustness analysis.

\section{Conclusions and perspectives}

This paper presents a global methodology developed in order to evaluate and compare numerous asphalt mixture alternatives. Various criteria that can be either qualitative or quantitative are considered such as energy consumption, GHG emissions, costs, mechanical performances, recyclability and production complexity. Note that some criteria are evaluated through a life cycle inventory analysis.

The developed model has been implemented in Visual Basic, allowing a considerable flexibility according to the project requirements or user preferences. The results obtained are straightforward and the multiple attribute decision making method further enable an assessment of the solution robustness. The developed methodology offers a pertinent, flexible and robust tool that helps to improve the decision making process, thus encouraging innovation. The tool is currently available and some applications are in progress.

\section{References}

Maystre, L. Y., Pictet J., and al. (1994a). Méthodes multicritères ELECTRE. In Presses Polytechniques et Universitaires Romandes.

Yang, J.-B., \& Singh, M. G. (1994b). An Evidential Reasoning Approach for Multiple-Attribute Decision Making with Uncertainty. In IEEE Transactions on systems, man, and cybernetics 24(1): 18.

Bueche, N. (2011). Evaluation des performances et des impacts des enrobes bitumineux tièdes. Thèse $\mathrm{N}^{\circ} 5169$. Ecole Polytechnique Fédérale de Lausanne.

Bueche, N. \& Dumont, A.-G., (2012a). Energy in warm mix asphalt. In Eurasphalt \& Eurobitume Congress. Istanbul.

Bueche, N. (2012b). Asphalt mixture choice: a decision-aid model. In IRF Bulletin Environment \& Climate Change. pp 15-18. 